\section{Economics of intolerance and social conflict}

\section{Partha Gangopadhyay}

$\mathrm{W}$ hy do people display intolerance, and why do they sometimes get trapped in cycles of violent and costly conflict? Why are some societies more (in)tolerant than others? These questions are neither well understood nor fully addressed by social scientists. Although some degree of intolerance is universal, serious violent, and commensurably costly, conflict occurs disproportionately in low-income states and pushes them further down the poverty trap. This article defines conflict by the level of intolerance displayed by one social group toward another such that non-negligible costs are imposed on at least one of the involved parties. An important consensus today is that intolerance and social conflict have a substantial economic dimension. One therefore expects economists to proffer a contribution to the collective bid to analyze intolerance and social conflict (for simplicity, hereafter simply referred to as conflict).

The starting point of the analysis here is that an act of intolerance by a person (called an agent) may beget either social approval or social disapproval. Approval brings a positive "return" to the agent whereas disapproval causes a welfare loss to the agent and hence a negative return. By imposing reasonable restrictions on these returns (costs or benefits to the agent), the article shows that several equilibria ranging from low to severe-intolerance equilibria - emerge from the static version of the model of a simplified society employed here. History, culture, and social beliefs and expectations play a decisive role in selecting one of these equilibria while even a momentary departure from an established equilibrium beyond a threshold level can engender sustained conflict.

Social norms and social contracts

Intolerance assumes a special and paramount importance in the context of globalization. Globalization has shrunk relative distances and has put heterogeneous stocks of people, that is, of diverse races and backgrounds, in increasingly close proximity. In the absence of an international arbiter and mediator, the progress and prosperity of globalization have been accompanied by heightened risks of conflict between and within states. People from different stocks of religion, ethnicity, and culture live as minorities among majorities and are thereby exposed to potential intolerance of varying degrees. ${ }^{1}$ If people are quarrelsome by nature, as Thomas Hobbes asserts in chapter 13 of The Leviathan, then globalization has given majorities unprecedented opportunity to commit acts of intolerance aimed at minorities, for example through diaspora financing of civil war. ${ }^{2}$

Hobbes suggests that there are three main causes of intolerance and conflict. First, the underlying theme of competition for limited resources motivates people to invade the physical space of others. Second, mutual distrust induces people to invade others' territory in the pursuit of (a perception of) safety. Third, people lock horns over achieving glory: invasion for reputation. It is the social contract and its enforcement that are believed to banish conflict from organized societies. However, if there is a problem with enforcing the social contract at a reasonably low cost, it is not possible to keep these causes of conflicts at bay.

In economics, theorizing about costly, violent conflict largely has been avoided by two powerful assumptions: first, all agents are construed as instrumentally rational and, second, all relevant information is made common knowledge. Indeed, Harsanyi's doctrine then posits that rational agents can correctly predict predictions of "equally informed and equally rational" others and thereby reach an equilibrium point at which, if conflict is costly, intelligent agents will stay away from conflict. ${ }^{3}$ (This is akin to chess players who at some stage of a game predict the end game as a dull draw and decide to declare it so - and thereby avoid the tedium of actually playing an infinite end game. ${ }^{4}$ ) The social contract is to prevent the vulnerable from molestation by the powerful. Rousseau popularized the idea of the social contract, now recognized as a major difference between the worlds of human and nonhuman animals. ${ }^{5}$

\section{Enforceability}

Here lurks Rousseau's famous paradox: in entering society, a person sacrifices all rights yet gives up nothing. ${ }^{6}$ Rousseau's solution is that each person be both legislator and subject and undertake his civil burden most diligently to express the true interests of his society by helping to voice its "general will." This solution does not necessitate an enforcement of the social contract by an omnipotent and omniscient state because agents, driven by their civil duties, ensure its enforcement on their own. But Thomas Hobbes realizes - also in chapter 13 of The Leviathan - that it is not an easy task to protect the vulnerable from the powerful in any society because the latter will willfully take on his civil burden. His suggestion is to create a "common power" through a social contract "to keep all in the awe." The need to enforce the socia contract by legislative mandate is widely recognized. Wherever such a mandate is impossible, a society strives to resolve the contract enforcement problem by creating and articulating other customs and social norms that influence individual behavior in 
the social context. Thus what action a person chooses can be seriously influenced by existing social customs and norms.

An example may be helpful. Consider a wage bargaining problem in which union leaders are bound by members' normative expectations to hold out against a management whose social position makes concessions equally unacceptable to their stake-holders. ${ }^{7}$ This is akin to the market for gifts which is usually governed by unwritten norms of gift giving: what is appropriate to give and to whom and on which occasion. Typically, these norms are iron-cast and uniquely determine individual behavior wherefrom a social outcome evolves, given a well-defined and enforceable penalty mechanism.

\section{Social interpretation of ethnic intolerance}

Interethnic intolerance is a complex phenomenon. The same action can have different social interpretations: a suicide bomber may appear as a martyr for one group and a criminal for the other. Such a clear separation of interpretations does not pose a problem. However, a problem arises when an action and its social reception and subsequent consequences are not clearly defined. The major innovation in this article is model how social customs and norms may allow for multiple possible social interpretations of an action an agent takes. As a result, an action can lead to multiple possible outcomes and it thus entails an intrinsic uncertainty that, in turn, can impinge on the social outcome. Put differently, in the model the social contract is not fully enforceable and its rules are subject to interpretations by the majority group. The model also entertains the idea that social norms and customs, which fill out the gaps in the social contract, themselves are subject to interpretations by the majority.

\section{Social interpretation and antisocial capital in ethnic intolerance}

The incompleteness of the social contract and a malleability of customs and social norms can give rise to an uncertainty that can profoundly influence individual decisionmaking which, in turn, shapes the outcome in the context of intolerance. We proffer a new name for this kind of behavior: antisocial capital. Social capital typically highlights those attributes or virtues in a society that forge a people into a community. ${ }^{8}$ These attributes dictate the relations among people wherefrom a course of actions gets chosen. The term antisocial capital in the context of intolerance means that a social agent displays vices (a type of attribute that influences the choice of action) that splits society into groups.

More specifically, an agent from the majority group metes out lack of trust and commitment, hostility, and/or economic harm to members of the minority so long as his reference or peer group (the majority) allows, tolerates, and possibly rewards his efforts. This is referred as antisocial capital because typically it opens up chinks in the social order and creates an insider-outsider kind of conflict. To benefit the insiders, antisocial capital is instrumentally used against the outsiders. If a minority group of people and a majority group of people make up a common total society, then antisocial capital disrupts the functioning of society at large. The syntactic import of antisocial capital is similar to the term antihero, a person who has superficial qualities of a hero.

\section{Intolerance as a form of preference interactions}

Consider an agent who derives some benefit from an economic transaction. This benefit is a called a normal return, or $\mathrm{R}^{\mathrm{N}}$. To highlight intolerance, the model generally hides this transaction-related benefit from the analysis and instead focuses on the agent's ability to also commit an act of intolerance, $T_{i}$. The return to intolerance is uncertain: if it receives social approval, the overall reward from the transaction is greater than $\mathrm{R}^{\mathrm{N}}$. Conversely, if the act of intolerance receives social censure, the overall reward is less than $\mathrm{R}^{\mathrm{N}}$. This construction allows for multiple social evaluations or interpretations of action $\mathrm{T}_{\mathrm{i}}$. In other words, preference interaction is assumed. Preference interaction takes place when an agent's preference ordering over alternatives in a choice set depends on actions or preferences of other agents. ${ }^{9}$

Intolerance can take fairly minor forms. Suppose an agent is in a shopping center to buy the weekend newspaper and a member of a minority group enters the store. An act of intolerance, $T_{i}$, can be a simple verbal slight: go back to your country. The return from this act of intolerance depends on how others respond to it. For example, social approval is typically communicated to the actor as well as to the victim by body language, snide comments, and the post-action treatment of the agent and the victim. Social approval is a positive feedback loop in preference interaction between the intolerant agent and the approving others. With social approval the return of the agent increases above $\mathrm{R}^{\mathrm{N}}$.

Conversely, others in the store may send the message of disapproval through body language, comments, confrontation, and post-action treatment of the agent and the victim. Social disapproval lowers the return below $\mathrm{R}^{\mathrm{N}}$. The agent thus faces a gamble when engaging in an act of intolerance: will intolerance beget approval or censure? This gamble may occur in many different kinds of situations. Imagine, for instance, a university where a minority member is refused tenure on account of racial intolerance. The chair of the tenure committee may face opposition from other committee members, in which case the chair may suffer loss of welfare. Alternatively, the chair may enjoy the warmth and cooperation of colleagues who support the refusal of tenure. Depending on how colleagues react, the act of intolerance may bring scorn or glory to the chair. As Schelling says, how the preferences interact determines the consequences that follow from the action. In the model presented here, the nature of the preference interaction is uncertain, that is, an agent does not know a priori how others will react. ${ }^{10}$ 


\section{Nash equilibrium outcomes with intolerance}

Economic models seek to describe how agents interact given a certain decision to be taken, such as one concerning intolerant behavior toward others. To do this, models rely on equilibrium analysis. Equilibrium analysis depends on the specification of agents' behaviors, expectations, utility functions, constraints, and the precise formulation of preference interactions. Given this, a so-called Nash equilibrium can then characterize the possible outcome(s) of the interaction process. There are two variants. The first postulates an outcome to occur when agents' actions are mutually consistent; the second occurs when agents have no incentive to unilaterally deviate from the outcome once they reach it. The model employed in this articles revolves around the first variant.

\section{A model of intolerance and social conflict}

In game theory, a Nash equilibrium implies a prediction of behavior for all agents such that, if every agent believes that the others will behave as predicted, it is then rational for each agent to behave according to this prediction. Thus, any belief, or prediction, which is not a Nash equilibrium cannot be rationally accepted by agents as an accurate prediction of what will happen because at least one agent will deviate from the prediction since it is not true. When a game with a unique equilibrium is developed, this equilibrium must be the only rational and correct prediction of how the agents will behave. But a problem arises in that the model develop here results in a multiplicity of possible predictions and hence multiple (equilibrium) outcomes.

In order to be able to display findings in terms of a two-dimensional diagram, some assumptions are made. The modeled society consists of only two agents and of a fringe group of minorities. The agents can commit acts of intolerance against minorities. As noted before, the behavior of the minorities themselves is not modeled. The reaction function of an agent is defined as the best response of one agent, in terms of intolerance toward minorities, given the level of intolerance chosen by the other agent. The Nash equilibrium is a combination of mutual best responses so that none has an incentive to unilaterally deviate from the outcome. The focus is placed upon the symmetric Nash equilibrium in which two agents choose an identical level of intolerance. Note that the model has several non-symmetric equilibria but these are not explicitly developed in the text (but see the Appendix).

An act of intolerance is akin to a gamble and can be formalized as follows:

ASSUMPTION 1: Agent i expects two possible returns from an act of intolerance, $\mathrm{T}_{\mathrm{i}} \cdot \mathrm{He}$ expects a possible return of $\mathrm{R}^{\mathrm{N}}+\Delta$ such that this sum is greater than $\mathrm{R}^{\mathrm{N}}$ alone. In other words, $\Delta$ is a positive return due to social approval of $\mathrm{T}_{\mathrm{i}}$. In contrast, agent $\mathrm{i}$ expects the return to be $\mathrm{R}^{\mathrm{N}}-\Delta$ if there is a social disapproval of $\mathrm{T}_{\mathrm{i}}$. Agent $\mathrm{i}$ further expects that social disapproval will materialize with a probability $\lambda$, and social approval with probability $1-\lambda$. The agent thus faces a gamble as $\mathrm{s} / \mathrm{he}$ either receives $\mathrm{R}^{\mathrm{N}}+\Delta$ with a probability $1-\lambda$ or receives $\mathrm{R}^{\mathrm{N}}-\Delta$ with probability $\lambda$.

OBSERVATION 1: The expected value of the gamble is $\mathrm{E}($.$) .$

$$
\mathrm{E}(.)=\mathrm{R}^{\mathrm{N}}+\Delta(1-2 \lambda)
$$

ProOF: By definition, $\mathrm{E}($.$) is:$

$$
\text { (1b) } \quad \mathrm{E}(.)=(1-\lambda)\left(\mathrm{R}^{\mathrm{N}}+\Delta\right)+\lambda\left(\mathrm{R}^{\mathrm{N}}-\Delta\right) \text {. }
$$

Simplification of (1b) yields (1a). Q.E.D.

ASSUMPTION 2: Agent $\mathrm{i}$ assumes that the probability of social disapproval $(\lambda)$ is positively related to the benefits $(\Delta)$ from intolerance $T_{i}$ :

$$
\text { (1c) } \lambda=\eta \Delta / 2 \text {, where } \eta>0 \text {. }
$$

OBSERVATION 2: The expected value of the gamble is reduced to the following:

$$
\mathrm{E}(.)=\mathrm{R}^{\mathrm{N}}+\Delta-\eta \Delta^{2}
$$

ProOF: Substituting (1c) in (1b) yields (1d). Q.E.D.

AsSUMPTION 3: The benefit from social approval is an increasing function of the average intolerance level, $\mathrm{T}^{*}=\left(\mathrm{T}_{1}+\mathrm{T}_{2}\right) / 2$ :

$$
\text { (1e) } \Delta=\mathrm{T}^{* 2} / 2 \text {. }
$$

ASSUMPTION 4: If, exclusive of the minority, there are $\mathrm{N}$ agents in society, the average resource cost to produce intolerance for each agent is $\mathrm{C}$, written as:

$$
\text { (2a) } \quad \mathrm{C}=\mathrm{C}_{0}-\mathrm{C}_{1}\left(\Sigma \mathrm{T}_{\mathrm{i}}\right)
$$

For a two-agent society, $\mathrm{C}$ reduces to the following:

$$
\text { (2a') } \mathrm{C}=\mathrm{C}_{0}-\mathrm{C}_{1}\left(\mathrm{~T}_{1}+\mathrm{T}_{2}\right) \text {. }
$$

Note that Assumption 2 and Assumption 3, respectively, introduce preference and cost interactions wherefrom agents' welfare interdependency arises. Assumption 2 says that the likelihood of social disapproval is an increasing function of the potential benefit from intolerance. Assumption 3 says that the individual benefit of intolerance 
for an agent exhibits increasing returns from the average level of intolerance, $\mathrm{T}^{*}$. Assumption 4 posits an interaction between cost functions of agents in producing intolerance.

CLAIM 1: The return from intolerance $\mathrm{T}_{\mathrm{i}}$ to agent $\mathrm{i}$ in a two-agent society is reduced to the following:

$$
\mathrm{R}_{\mathrm{i}}=\mathrm{R}^{\mathrm{N}}+\left[\left(\mathrm{T}^{*}\right)^{2} / 2\right]-\left[\eta\left(\mathrm{T}^{*}\right)^{4} / 4\right]-\left(\mathrm{C}_{0} \mathrm{~T}_{\mathrm{i}}\right)+\left(\mathrm{C}_{1} \mathrm{~T}_{\mathrm{i}}^{2}\right)+\left(\mathrm{C}_{1} \mathrm{~T}_{\mathrm{i}} \mathrm{T}_{\mathrm{j}}\right),
$$

where $T^{*}$ is the average level of intolerance shown by agent $i$ and agent $j$.

PROOF: (2b) is derived after substituting (1e), (2a), and (2a') into (1d).

CLAIM 2: For a symmetric Nash equilibrium with two identical agents the reaction function of each agent is identical, and the (Nash) equilibrium condition is given in terms of the average level of intolerance $\mathrm{T}^{*}$ as follows:

(2c) $\quad \mathrm{T}^{*}\left(3 \mathrm{C}_{1}+0.5\right)-\eta\left(\mathrm{T}^{*}\right)^{3}-\mathrm{C}_{0}=0$.

PROOF: See Appendix. Q.E.D.

From (2c) we can express the equilibrium condition as

$\left(2 c^{\prime}\right) \quad \mathrm{M}\left(\mathrm{T}^{*}\right)=\mathrm{T}^{*}\left(3 \mathrm{C}_{1}+0.5\right)-\eta\left(\mathrm{T}^{*}\right)^{3}=\mathrm{C}_{0}$.

The function $\mathrm{M}\left(\mathrm{T}^{*}\right)$ is drawn in Figure 1. Note that there is a critical value of average intolerance $\left.\mathrm{T}^{*}-\mathrm{A}=\left[\mathrm{C}_{1}+0.16\right) / \eta\right]^{1 / 2}$ - such that:

(2d) $\mathrm{dM}\left(\mathrm{T}^{*}\right) / \mathrm{dT}^{*}>0$ for $\mathrm{T}^{*}<\mathrm{A}$ [the rising part of $\mathrm{M}\left(\mathrm{T}^{*}\right)$ in Figure 1] and

(2d') $\quad \mathrm{dM}\left(\mathrm{T}^{*}\right) / \mathrm{dT}^{*}<0$ for $\mathrm{T}^{*}>\mathrm{A}$ [the falling part of $\mathrm{M}\left(\mathrm{T}^{*}\right)$ in Figure 1].

The two intersection points between $\mathrm{M}\left(\mathrm{T}^{*}\right)$ and the horizontal line given by the value of $\mathrm{C}_{0}$ determine the symmetric equilibria, $\mathrm{E}_{1}$ - the point at which $\mathrm{KK}^{\prime}, \mathrm{C}_{0}$, and $\mathrm{M}\left(\mathrm{T}^{*}\right)$ cross each other - and $\mathrm{E}_{2}$ - where $\mathrm{C}_{0}$, and $\mathrm{M}\left(\mathrm{T}^{*}\right)$ cross again — in Figure 1. The horizontal axis measures the average level of intolerance, $\mathrm{T}^{*}$. The vertical axis measures the average cost of being an intolerant person. Thus, up to the average intolerance level of A (indicated by the vertical line at point A), the average cost of being intolerant rises as measured on the vertical axis. But beyond $\mathrm{A}$, the average cost of being intolerant falls as the average level of intolerance against minorities in the society increases.

The first equilibrium, $\mathrm{E}_{1}$, at an average intolerance level of $\mathrm{K}$ is unstable. For example, between points $\mathrm{K}$ and $\mathrm{A}$, the direction of the arrows in the Figure all point

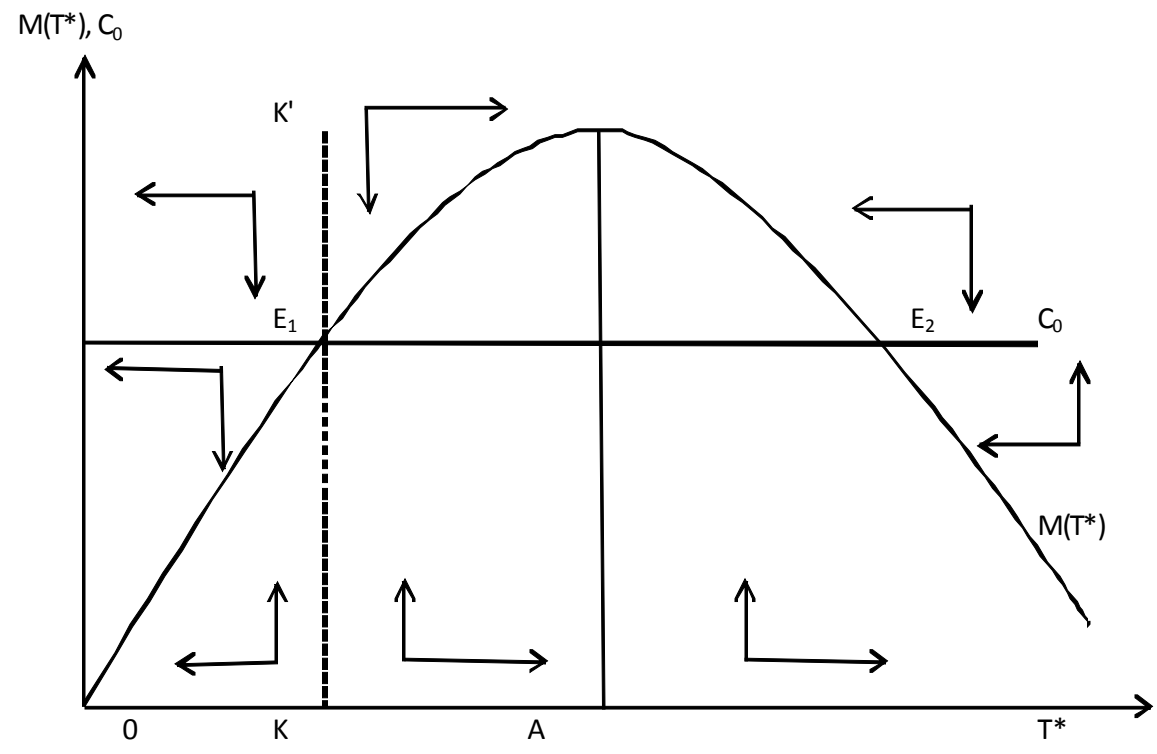

Figure 1: Equilibria for intolerance game.

away from $\mathrm{E}_{1}$. In contrast, the second equilibrium, $\mathrm{E}_{2}$, is stable. Whenever there is a movement away from $\mathrm{E}_{2}$, the direction of the arrows indicates a return to $\mathrm{E}_{2}{ }^{11}$

In the presence of multiple equilibria (symmetric and non-symmetric), the model fails to offer a single prediction. (Nash was aware of this problem as he tried to resolve it by offering sufficient conditions to characterize a unique equilibrium outcome out of several equilibria. ${ }^{12}$ ) The model employed here yields the following results:

RESULT 1: By construction, there are several possible solutions to the polynomial reaction functions ( $3 b)$ and ( $\left.3 b^{\prime}\right)$ given in the Appendix. In Figure 1, only the symmetric equilibria $\mathrm{E}_{1}$ and $\mathrm{E}_{2}$ are considered. From the Appendix we know that $\mathrm{E}_{1}$ is unstable and $E_{2}$ is stable which creates the vertical, dotted boundary line $\mathrm{KK}^{\prime}$ ' in Figure 1. If the historical profile of average intolerance, that is, people's expectations or beliefs about average intolerance, are contained along the stretch 0 to $\mathrm{K}$ on the $\mathrm{T}^{*}$ axis, then the system gradually converges from relatively low intolerance states to zero intolerance states, an ideal outcome.

RESULT 2: If history, or beliefs or expectations, about average intolerance have initial values of $\mathrm{T}^{*}>\mathrm{K}$, then the system moves toward the high-intolerance - and stable - symmetric equilibrium, $\mathrm{E}_{2}$. 
RESULT 3: If history, or beliefs or expectations, about average intolerance goes beyond certain limits, the system will gravitate toward non-symmetric equilibria. Given the nature of the polynomials, one cannot explicitly derive the boundaries for non-symmetric equilibria. (To recall, symmetric means that intolerant agents harbor equal levels of intolerance; non-symmetric agents display unequal levels of intolerance.)

The tyranny of multiple of equilibria and the culture of violence

The analytic problem with multiple equilibria is well-recognized in economics when one considers games with several agents. The upshot is that many different variants, or types, of behavior among these agents can be rationally sustained as combinations of mutual best responses.

To bring out the main message of the model, violence in the context of intolerance is introduced because the more serious forms of intolerance are carried out by means of violent methods. Every culture and society has a code of behavior with regard to violence. One can thus think of the boundary KK' in Figure 1 as a critical threshold of violence. Violent intolerance up to level $\mathrm{K}$ can flare up but eventually will dissipate toward zero again because equilibrium $\mathrm{E}_{1}$ is not stable. In contrast, violent intolerance beyond level $\mathrm{K}$ will become ingrained and sustained. Note that while the degree or even culture - of violent intolerance is exogenous to the model, the boundary KK' is determined by the mathematics of the model, i.e., the threshold level is endogenously determined.

Low average intolerance levels of up to KK' are feasible if agents come to share a common prediction that others will not cross the boundary KK'. If all agents believe that KK' is the social limit, then all will choose as an optimal behavior intolerance levels that decline toward zero. In contrast, if agents believe that other agents will cross the boundary KK', the reward from expected social approval of intolerance can ratchet up and society can be ravaged by high levels of continuous violent intolerance. Whether (other) agents will cross the boundary KK' is usually a matter of culture. If the "culture of violence" is low and if the boundary KK' is exceeds this culturally acceptable limit, then society will engage in relatively peaceful resolution of potential conflict. In the opposite case, violent intolerance can become a continuous and stable, equilibrium phenomenon. What one expects about others' behavior determines one's own behavior and, thereby, the consequent equilibrium levels of intolerance and conflict in the model. Social expectations and the culture of violence are thus important factors in shaping individual predictions about the behavior of others regarding an "acceptable" level of violence.

Although not demonstrated in this article, it turns out that the discussion regarding the boundary KK' also applies to the non-symmetric equilibria of the reaction functions. An intermediate equilibrium of intolerance can get established in an analogous manner when agents use the relevant shared beliefs, or predictions, about others' behavior. For the first time, we thus have a model that explains variations across societies in the incidence of intolerance and costly conflict as a consequence of multiple equilibria. The selection of a specific equilibrium cannot be dissociated from the cultural views of any society toward violence. Criteria regarding what counts as an "acceptable" level of violence become crucial determinants of each agent's prediction and subsequent behavior because $\mathrm{s} / \mathrm{he}$ expects everyone else's behavior to be influenced by the same cultural norm of violence. In a word, the model makes clear why peer and herd-effects are so important. ${ }^{13}$

\section{Models of conflict}

Standard economic models of conflict are usually cast as general equilibrium models, with presumed perfectly competitive markets, and involve a trade-off between unproductive and productive ("guns versus butter") activity. Hirshleifer put forward several models to explain conflict in terms of three economic variables: (1) preferences, (2) opportunities within constraints, and (3) prevailing perceptions, and he explained an equilibrium conflict as a Nash equilibrium of a contest such that agents' efforts (i.e., gun acquisition) and the corresponding levels of defense spending are chosen by rivals as mutual best responses. Grossman expanded the basic Hirshleifer model of optimal defense spending to more intricate situations. Conflicts are a product of rebellion akin to an industry that creates profit-making opportunities from an act of piracy, or of looting. Here, a state's optimal defense spending is a Nash equilibrium of a noncooperative game played between a government and a rebel group. Skaperdas introduced the possibility of cooperation, as opposed to conflict, in a game that repeats over time, and Garfinkel extended the analysis to the international arena by introducing domestic politics as a determinant of a state's defense spending. ${ }^{14}$

Against this backdrop of economic theory, political scientists traditionally argue that conflict and rebellion are actuated by political protests that are driven by deep-rooted grievances of people. These are precipitated by a host of social banes like inequality and racial, ethnic, or religious intolerance. This literature has highlighted two elements in exacerbating conflict. First, the type of political regime has been isolated as a determinant of conflicts. For example, there is some evidence to believe that more democratic countries have a lower risk of war. Second, economic inequality 
is believed to be an important determinant of intrastate conflict, although recent economic studies have not found any systematic relation between inequality and conflict. ${ }^{15}$ However, Collier and Hoeffler have noted that low per capita income and low growth rates are contributing factors to conflict.

In contrast to the extant literature, the model presented in this article posits violent, costly conflict as a form of intolerance by one social group toward another. The act of intolerance is carried out by individual agents who are members of a social group, and this lays down the foundation for the rational decisionmaking assumption in the model. The model understands and predicts the behavior of an agent by assuming that $\mathrm{s} /$ he is motivated by the expected consequence of his/her action. Up to this point the model mirrors standard economic models of conflict. But it then departs as the standard models rely on a specific form of conflict technology to characterize the Nash equilibrium. ${ }^{16}$ In contrast, the model used here treats conflict in the form of an average level of intolerance, and the return from intolerance to an agent is modeled as a gamble: depending on the nature of preference interactions between the agent and his/her peers, there follows either a gain or a loss from an act of intolerance. The interactive framework of the model is predicated upon two assumptions that characterize the social dimensions of intolerance and conflict. First, it is assumed that the likelihood of social disapproaval of intolerance is an increasing function of the size of the gain that an agent makes from the gamble, which may be viewed as "builtin" social justice in the model. ${ }^{17}$ Second, it is assumed that the size of the gain to an agent, or the return from the gain, from an act of intolerance is an increasing function of the average intolerance in a society. This is the specific form of preference interaction the model works with. From these assumptions and postulated functional forms derive the results of the model, in particular that history, culture, and social beliefs or expectations can play an important role in fueling, abetting, or arresting intolerance and violent conflict in a society.

\section{Conclusion}

It is well-documented in economics that fully rational and well-informed agents may display intolerance and engage in costly and violent conflict because they prefer conflict to peace, provided the potential penalties are not too high at the margin. It is well-recognized that intolerance and conflict can also arise from the desire to build reputation and also because of imperfect information. It has also been anticipated by the game-theoretic literature that multiple equilibria can be a source of conflict. In this article a model has been developed to show just how multiple equilibria can be "a fact of life to be appreciated," as Myerson articulated the role of multiple equilibria in the context of social justice. ${ }^{18}$

The model stresses the role of uncertainty that can accompany intolerance and conflict. An act of intolerance by an agent may beget social censure or social approval. Approval brings a positive return; censure causes a welfare loss and hence a negative (or at any rate, low) return. In a static model, by imposing reasonable restrictions on these costs and benefits, a multiplicity of equilibrium intolerance states, ranging from low to severe-intolerance equilibria, can be derived. The role of cultures of violence assumes importance in selecting the ultimate equilibrium a society arrives at. History and social expectations can play a significant role in selecting one of them, and even a momentary departure beyond a threshold level of intolerance can engender sustained violent and costly social conflict.

\section{Appendix: Proof of Claim 2}

The optimization problem of agent $i$ is to maximize the net return function (2b) by choosing $T_{i}$ holding $T_{j}$ constant, a case commonly known as zero-conjectural variation. That is:

$$
\underset{\{\mathrm{Ti}\}}{\operatorname{Maximize}} \mathrm{R}_{\mathrm{i}}=\mathrm{R}^{\mathrm{N}}+\left[\left(\mathrm{T}^{*}\right)^{2} / 2\right]-\left[\eta\left(\mathrm{T}^{*}\right)^{4} / 4\right]-\left(\mathrm{C}_{0} \mathrm{~T}_{\mathrm{i}}\right)+\left(\mathrm{C}_{\mathrm{i}} \mathrm{T}_{\mathrm{i}}^{2}\right)+\left(\mathrm{C}_{\mathrm{i}} \mathrm{T}_{\mathrm{i}} \mathrm{T}_{\mathrm{j}}\right)
$$

The first-order condition for maximizing the net return by agent $\mathrm{i}$ gives us the (implicit) reaction function of agent $i$ as:

$$
\mathrm{dR}_{\mathrm{i}} / \mathrm{dT}_{\mathrm{i}}=\left(\mathrm{T}^{*} / 2\right)-\left[\eta\left(\mathrm{T}^{*}\right)^{3} / 2\right]-\mathrm{C}_{0}+2 \mathrm{C}_{1} \mathrm{~T}_{\mathrm{i}}+\mathrm{C}_{1} \mathrm{~T}_{\mathrm{j}}=0
$$

because $\mathrm{dT}^{*} / \mathrm{dT}_{\mathrm{i}}=\mathrm{d}\left[\left(\mathrm{T}_{\mathrm{i}}+\mathrm{T}_{\mathrm{j}}\right) / 2\right] / \mathrm{dT}_{\mathrm{i}}=1 / 2$.

In an analogous manner the reaction function, in the implicit form, for agent $\mathrm{j}$ is given as

$$
\text { (3b') } \quad \mathrm{T}^{*} / 2-\left[\eta\left(\mathrm{T}^{*}\right)^{3} / 2\right]-\mathrm{C}_{0}+2 \mathrm{C}_{1} \mathrm{~T}_{\mathrm{j}}+\mathrm{C}_{1} \mathrm{~T}_{\mathrm{i}}=0 \text {. }
$$

Note that equations ( $3 b$ ) and ( $3 b^{\prime}$ ') must be solved simultaneously to arrive at the Nash equilibrium after substituting $\left.T^{*}=\left[\left(T_{i}+T_{j}\right)\right] / 2\right]$ into $(3 b)$ and (3b'). Although there are six possible solutions, or equilibria, as we know from their powers, these polynomials cannot be explicitly solved. The second-order condition eliminates 2 of them as being unstable and we can give qualitative results. The second-order condition requires that

$$
\mathrm{d}^{2} \mathrm{R}_{\mathrm{i}} / \mathrm{dT}_{\mathrm{i}}^{2}<0
$$

In order to provide the qualitative results, we consider only symmetric Nash equilibria that call forth

$$
\mathrm{T}_{\mathrm{i}}=\mathrm{T}_{\mathrm{j}}=\mathrm{T}^{*} .
$$


(C) www.epsjournal.org.uk - Vol. 4, No. 2 (2009)

Substituting (3d) into (3b) or (3b') yields the condition for a symmetric Nash equilibrium as:

(4a) $\quad \mathrm{T}^{*} / 2-\left[\eta\left(\mathrm{T}^{*}\right)^{3} / 2\right]-\mathrm{C}_{0}+3 \mathrm{C}_{1} \mathrm{~T}^{*}=0$.

That is,

(4b) $\quad \mathrm{T}^{*} / 2-\left[\eta\left(\mathrm{T}^{*}\right)^{3} / 2\right]+3 \mathrm{C}_{1} \mathrm{~T}^{*}=\mathrm{C}_{0}$.

(4c) $\quad \mathrm{M}\left(\mathrm{T}^{*}\right)=\mathrm{C}_{0}$,

where

(4d) $\quad \mathrm{M}\left(\mathrm{T}^{*}\right)=\mathrm{T}^{*} / 2-\left[\eta\left(\mathrm{T}^{*}\right)^{3} / 2\right]+3 \mathrm{C}_{1} \mathrm{~T}^{*}$.

In Figure 1, (4d) is plotted along with $\mathrm{C}_{0}$ as a horizontal line. The shape of (4d) is arrived at after differentiating $(4 \mathrm{c})$ with respect to $\mathrm{T}^{*}$ :

(4e) $\quad \mathrm{dM}\left(\mathrm{T}^{*}\right) / \mathrm{dT}^{*}=\left(3 \mathrm{C}_{1}+0.5\right)-3 \eta \mathrm{T}^{* 2}$.

Note that there is a critical value of $\left.\mathrm{T}^{*}-\mathrm{A}=\left[\mathrm{C}_{1}+0.16\right) / \eta\right]^{1 / 2}-$ for which $\mathrm{dM}\left(\mathrm{T}^{*}\right) / \mathrm{dT}^{*}=0$. For $\mathrm{T}^{*}<\mathrm{A}, \mathrm{dM}\left(\mathrm{T}^{*}\right) / \mathrm{dT}^{*}>0$ and for $\mathrm{T}^{*}>\mathrm{A}, \mathrm{dM}\left(\mathrm{T}^{*}\right) / \mathrm{dT}^{*}<0$. As a result, $\mathrm{M}\left(\mathrm{T}^{*}\right)$ is drawn as a hump-shaped function in Figure 1 and the points of intersection between the hump-shaped function and the horizontal line $\mathrm{C}_{0}$ yield the symmetric equilibria $E_{1}$ and $E_{2}$. The second-order condition requires that $\mathrm{d}^{2} \mathrm{R}_{\mathrm{i}} / \mathrm{dT}^{* 2}$ $<0$ and hence

$$
\mathrm{T}^{* 2}>\left[4\left(0.25+2 \mathrm{C}_{1}\right) / 3 \eta\right]
$$

$E_{2}$ is the stable, symmetric equilibrium that satisfies (4f) while $E_{1}$ fails to satisfy (4f). Besides these symmetric equilibria there are several non-symmetric equilibria that are not explicitly derivable from the polynomial reaction functions. Q.E.D.

\section{Notes}

Partha Gangopadhyay is Senior Lecturer in the School of Economics and Finance, University of Western Sydney. Prior to his current post, he was Professor and Chair of Empirical Economics and Social Research, Faculty of Economics, Europa-Universität Viadrina, Frankfurt/O, Germany. His research interests comprise economic theory, applied game theory, and economics of conflicts. He has authored four books and fifty refereed articles and book chapters. He is Chief Editor of the International Journal of Conflict, Economic Development and Peace Science. The author is grateful to Michael Intriligator and Jurgen Brauer for comments without which the article would not have reached its current form. The usual disclaimer applies.

1. One may wonder why the logic does not apply to old societies with villages that border on each other. Alternatively, one may like to reduce the problem into the usual insider-outsider dynamics. It is important to note that both old societies and insider-outsider models have prior behavioral norms that usually guide and dictate individual behavior. In contrast, the model in this article deals with the case of when such prior norms do not exist. The current phase of globalization is an important point in history in that it juxtaposes heterogeneous people living in close proximity without the benefit of preexisting social norms that can guide optimal responses of individuals or social groups to each other. The goal of the model is to explain potential problems of this historical epoch. The problems at hand have already surfaced in the form of the London subway bombing, Madrid train attack, and Mumbai mayhem and the continuous cycle of ethnic "cleansing" in various parts of the world today. The model is sufficiently robust to be applicable to any other setting for which members of a social group display intolerance and hostility toward other social groups.

2. Note that a minority group also can be intolerant, but this is not modeled here.

\section{Harsanyi (1961).}

4. As opposed to the work of J. Hirshleifer $(1989,1995,2000)$ who argued that the conflict technology employed can give rise to economic benefits, traditional economic models presuppose conflict as welfare-reducing for all parties.

5. Rousseau (1964). In the nonhuman animal world, competition for food, mating opportunities, and living space is intense yet we hardly come across serious organized conflict. On the individual level, size asymmetry often resolves conflict nonviolently and within a short span of time: the smaller organism recognizes, assesses, and submits to the larger one, leaving the latter with the prize. When the asymmetry is sufficiently small, protracted violent conflict can occur. Organized mass intraspecies violence is rare, although chimpanzees, wolves, and other species hunt in packs with violence directed against other species. Among humans, the social contract can be a written code of behavior and, if enforceable, can resolve problems. Among nonhuman social species, such as dolphins, bees, termites, and ants, social norms or rules can be neurally wired and influence or dictate the behavior of individual animals. See D. Hirshleifer (2008).

6. See Cobban (1934). 
7. See, e.g., Akerlof (1980).

8. See, e.g., Putnam (1993); Bowles (1999); Durlauf (1999).

9. See Schelling (1971). Future research work may explore a specific form of preference interaction to explain intolerance and conflict. Consider two types of agents with different attitudes toward intolerance: namely an "intolerance leader" and an "intolerance follower." One could posit that an intolerance leader is risk-loving while an intolerance follower is risk averse and model preference reversals and interactions to explain the trigger factors to ethnic conflict.

10. This is similar to Mark Twain's story of The Connecticut Yankee (1917) wherein a Yankee sought to bring education, modern technology, and a higher standard of living to King Arthur's realm. Initially supported by a band of young converts, he was subsequently drowned by a despotic church and its noble beneficiary who opposed his actions due to "deep-rutted habits." The Yankee failed because he could not change the outlook of a large enough number of King Arthur's subjects. Ultimately, his actions met up with overwhelming social disapproval.

11. Apart from the two symmetric equilibria, several non-symmetric equilibria exist, as shown in the Appendix. In the text, emphasis is placed upon the symmetric Nash equilibria in Figure 1.

\section{Nash (1953).}

13. There are many settings in which the multiplicity of equilibria can be a source of problems, for example, in implementation theory (Palfrey, 1992), principal-agent theory (Mookherjee, 1984), differential-information economies (Postlewaite and Schmeidler, 1986), and mechanism design (Demski and Sappington, 1984). There also exists an extensive literature on mechanism design exploring mechanisms that can uniquely implement an outcome (Ma, 1988; Ma, Moore, and Turnbull, 1988).

14. Hirshleifer (1988; 1989; 1995; 2000); Grossman (1991; 1998; 2004); Skaperdas (1992); Garfinkel (1994).

15. Regime type: e.g., Hegre, et al. (2001). Lower risk of war: e.g., Collier and Hoeffler (1998; 2002). No systematic relation: see Collier and Hoeffler (2002).

16. The standard models posit conflicts as a contest over winning a prize, similar in spirit to a football match. The likelihood of winning the contest is introduced via a contest success function (CSF) that J. Hirshleifer (1989) called a conflict technology. This is assumed to be a function of (war) efforts of all agents involved in the contest.
The CSF motivates each agent to anticipate that the consequences of one's action will depend on others' actions. Each agent's incentive to undertake war efforts will depend on others' behavior, which in turn depend on their incentives to arm themselves. The model thus becomes interactive, and the Nash equilibrium concept then becomes important in explaining the outcome.

17. I would concur with one who likes to think that this is rather envy and not social justice.

18. Reputation: Bowles and Gintis (1988); Crampton (1984); Crawford, (1982). Multiple equilibria as source of conflict: Hollis (1987). Myerson: Myerson (2004).

\section{References}

Akerlof, G. 1980. "A Theory of Social Custom of which Unemployment may be one Consequence." Quarterly Journal of Economics. XCIV, pp. 749-775.

Bowles, S. 1999. "Social Capital and Community Governance.” Focus. Vol. 20, pp. 6-10.

Bowles, S. and H. Gintis. 1988. "Contested Exchange: Political Economy and Modern Economic Theory." American Economic Review. Vol. 78, pp. 145-150.

Collier, P. and A. Hoeffler. 1998. "On Economic Causes of Civil War." Oxford Economic Papers. Vol. 50, pp. 563-573.

Collier, P. and A. Hoeffler. 2000. "Greed and Grievance in Civil Wars." World Bank Working Paper Series, No. 18. Washington, D.C.: World Bank.

Cobban, A. 1934. Rousseau and the Modern State. London: Allen \& Unwin.

Cooper, R. and J. Haltiwanger. 1996. "Evidence on Macroeconomic Complementarities." Review of Economics and Statistics. Vol. 78, pp. 78-93.

Cooper, R. and A. John. 1988. "Coordinating Coordination Failures in Keynesian Models.” Quarterly Journal of Economics. Vol. 103, pp. 441-463.

Crampton, P. 1984. "Bargaining with Incomplete Information: An Infinite Horizon Model with Two-Sided Uncertainty." Review of Economic Studies. Vol. 51, No.4 pp. 579-593.

Crawford, V. 1982. "A Theory of Disagreement in Bargaining." Econometrica. Vol. 50, pp. 607-631.

Durlauf, S. 1999. “The Case against Social Capital.” Focus. Vol. 20, pp. 1-5.

Garfinkel, M.R. 1994. “'Domestic Politics and International Conflict." American Economic Review. Vol. 84, pp. 1294-1309.

Grossman, H.I. 1991. “A General Equilibrium Model of Insurrections.” American Economic Review. Vol. 81, pp. 912-921.

Grossman, H.I. 1998. "Producers and Predators." Pacific Economic Review. Vol. 3, pp. 169-187.

Grossman, H.I. 2004. “Peace and War in Territorial Disputes.”NBER working paper, 
No. 10601.

Harsanyi, J. 1961. "On the Rationality Postulates Underlying the Theory of Cooperative Games.” Journal of Conflict Resolution. Vol. 5, pp. 179-196.

Hegre, H., T. Ellingsen, N.P. Gleditsch, S. Gates. 2001. "Towards a Democratic Civil Peace? Opportunity, Grievance, and Civil War, 1816-1992.” American Political Science Review. Vol. 95, pp. 16-33.

Hirshleifer, D. 2008. "Psychological Bias as a Driver of Regulation." European Financial Management. Vol. 14, No. 5, pp. 854-874.

Hirshleifer, J. 1988. "The Analytics of Continuing Conflict.” Synthesis. Vol. 76, pp. 201-233.

Hirshleifer, J. 1989. "Conflict and Rent-Seeking Success Functions: Ratio versus Difference Models of Relative Success.” Public Choice. Vol. 63, pp. 101-112.

Hirshleifer, J. 1995. “Anarchy and its Breakdown." Journal of Political Economy. Vol. 103, pp. 27-52.

Hirshleifer, J. 2000. "The Macrotechnology of Conflict." Journal of Conflict Resolution. Vol. 44, pp. 773-792.

Hollis, M. 1987. The Cunning of Reason. Cambridge: Cambridge University Press. Hume, D. 1888. Treatise on Human Nature. Oxford: Oxford University Press.

Ma, C. 1988. "Unique Implementation of Incentive Contracts with Many Agents." Review of Economic Studies. Vol. 55, pp. 555-572.

Ma, C., J. Moore, and S. Turnbull. 1988. "Stopping Agents from Cheating." Journal of Economic Theory. Vol. 46, pp. 355-372.

Mookherjee, D. 1984. “Optimal Incentive Schemes with Many Agents." Review of Economic Studies. Vol. 51, pp. 433-446.

Myerson, R.B. 1991. Game Theory: Analysis of Conflict. Boston, MA: Harvard University Press.

Myerson, R.B. 1992. “On the Value of Game Theory in Social Science.” Rationality and Society. Vol. 4, No. 1, pp. 62-73.

Myerson, R.B. 2004. "Justice, Institutions and Multiple Equilibria.” Chicago Journal of International Law. Vol. 5, No. 1, pp. 91-107.

Nash, J.F. 1953. "Two-person Cooperative Games.” Econometrica. Vol. 21, pp. 128-140.

Newman, J. 1957. "Book review, 'The Lisbon Earthquake' by Sir T.D. Kendrick." Scientific American. July. Pp. 164-169.

Palfrey, T.R. 1992. "Implementation in Bayesian Equilibrium: The Multiple Equilibrium Problem in Mechanism Design," in J.J. Laffont, ed., Advances in Economic Theory. Cambridge: Cambridge University Press.

Postlewaite, A. and D. Schmeidler. 1986. "Implementation in Differential Information Economies.” Journal of Economic Theory. Vol. 39, pp. 14-33.

Putnam, R. 1993. "The Prosperous Community: Social Capital and Public Life." The American Prospect. Vol. 13, pp. 35-42.

Rousseau, J.J. 1964. The First and Second Discourses. Edited by R.D. Masters. New
York: St Martin's Press.

Schelling, T. 1971. "Dynamic Models of Segregation." Journal of Mathematical Sociology. Vol. 1, pp. 143-186.

Skaperdas, S. 1992. "Cooperation, Conflict and Power in the Absence of Property Rights." American Economic Review. Vol. 82, pp. 720-739.

Skaperdas, S. and C. Syropoulos. 1997. "The Distribution of Income in the Presence of Appropriative Activities." Economica. Vol. 64, pp. 101-107.

Twain, M. 1917. A Connecticut Yankee in King Arthur's Court. New York: Modern Library Edition. 